\section{Gategory}

Synthesis of Natural

Products and

Potential Drugs

\section{Key words}

\section{pinnatoxin A}

Ireland-Claisen rearrangement

asymmetric 1,2-addition

spiroacetals

macrocycles

SYNFACThen
of the month

C. E. STIVALA, A. ZAKARIAN* (FLORIDA STATE UNIVERSiTY, TALLAHASSEE, USA)

Total Synthesis of (+)-Pinnatoxin A

J. Am. Chem. Soc. 2008, 130, 3774-3776.

\title{
Synthesis of (+)-Pinnatoxin A
}

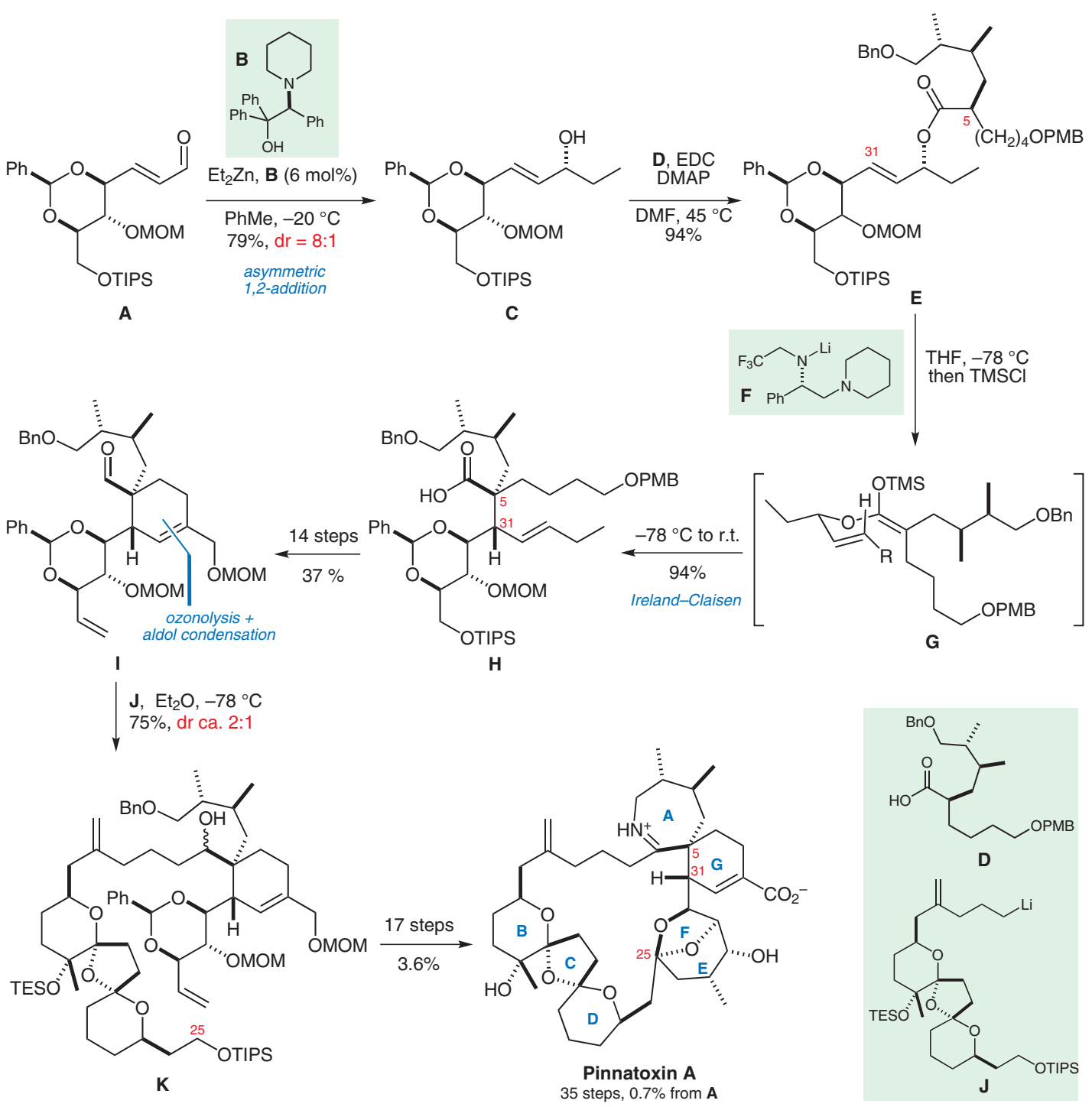

Significance: $(+)$-Pinnatoxin $A$ is a neurotoxin found in the Pinna shellfish species, presumably acting as a calcium-channel activator. The present study concentrates on a new approach towards ring $\mathrm{G}$ using an Ireland-Claisen rearrangement to establish the C5 and C31 stereogenic centers.
Comment: A was synthesized from D-ribose. Deprotonation of $\mathbf{E}$ using chiral amide $\mathbf{F}$ followed by treatment with $\mathrm{TMSCl}$ furnished silylketene acetal G which underwent stereoselective [3,3]-sigmatropic rearrangement upon warming to room temperature. 